\title{
ХВИЛЕВІДНИЙ ФІЛЬТР ДІАПАЗОНУ 4-6 ГГЦ
}

С.І. Пільтяй, А.В. Булашенко, А.В. Поліщук, І.В. Фесюк

Київський політехнічний інститут ім. Ігоря Сікорського

s.piltiai@kpi.ua, a.bulashenko@kpi.ua, animeshka177al@gmail.com

Сьогодні поляризаційні антенні системи широко використовуються у різноманітних радіолокаційних, радіонавігаційних та супутникових телекомунікаційних системах [14]. Одними із елементів, що $є$ у цих антенах є хвилевідні фільтри та поляризатори. Хвилеводні фільтри необхідні, щоб виділяти певну смугу частот. Пристрої обробки поляризації використовуються, щоб отримати фазовий зсув на виході $90^{\circ}$ [5-7]. Серед хвилеводних поляризаторів є пристрої із діафрагмами [8-10], пристрої зі штирями $[1,2]$ та комбіновані пристрої [11-13].

Структурні схеми хвилеводних фільтрів із діафрагмами 3-го, 5-го та 7-го порядків подані на рис. 1. Подана схема за допомогою теорії мікрохвильових кіл була одержана [14-16] (рис. 1).

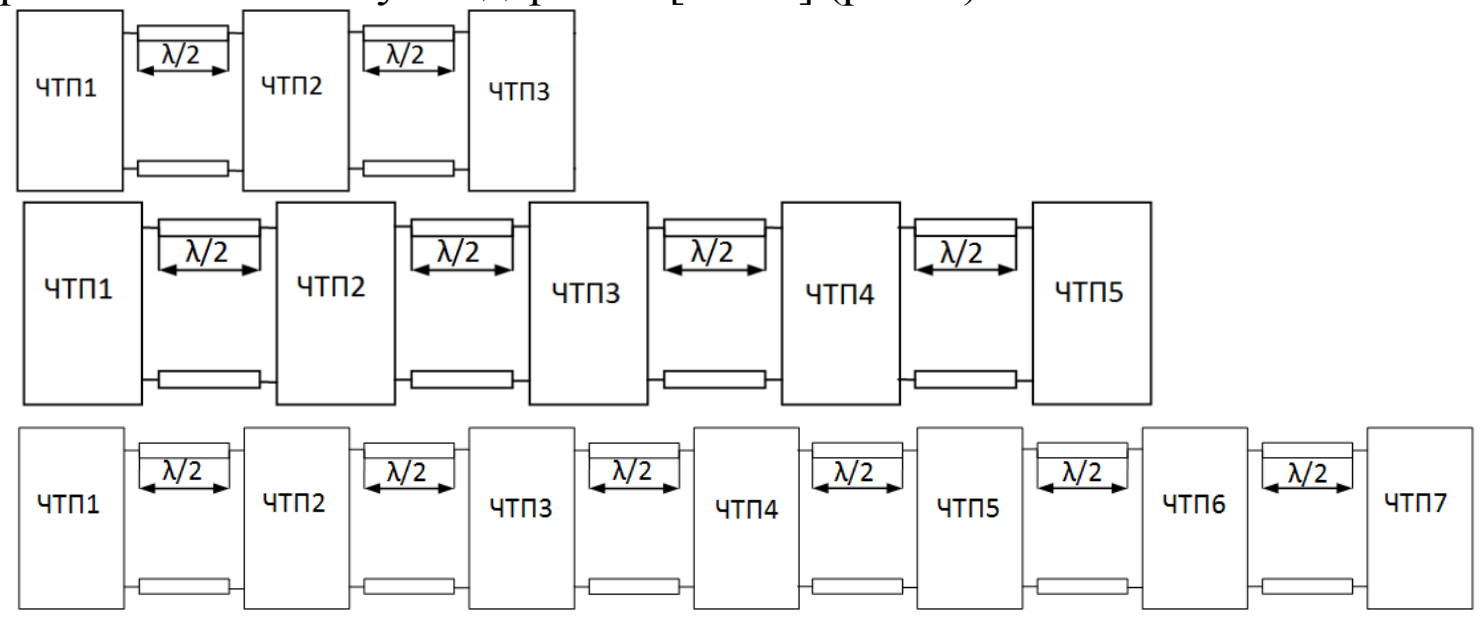

Рис. 1

На рис. 2 наведена частотна залежність амплітудної характеристики фільтру у робочому діапазоні частот 4-6 ГГц. Із рис. 3 бачимо, що порядок фільтрів $\mathrm{n}$ збільшується від 3 до 7. При цьому частотна вибірність та смуга пропускання покращуються по двом напрямкам. Перший полягає в тому, що відносна смуга пропускання теоретичного фільтру та спроектованого фільтру поза смугове відхилення стає більш гострим. Покращення частотної селективності досягається за рахунок фазового зсуву. Встановлено, що пропускна спроможність для фазового зсуву $90^{\circ} \pm 5^{\circ}$ постійно погіршується 3 $30 \%$ до $26 \%$ та $25 \%$ (рис. 2 ). 


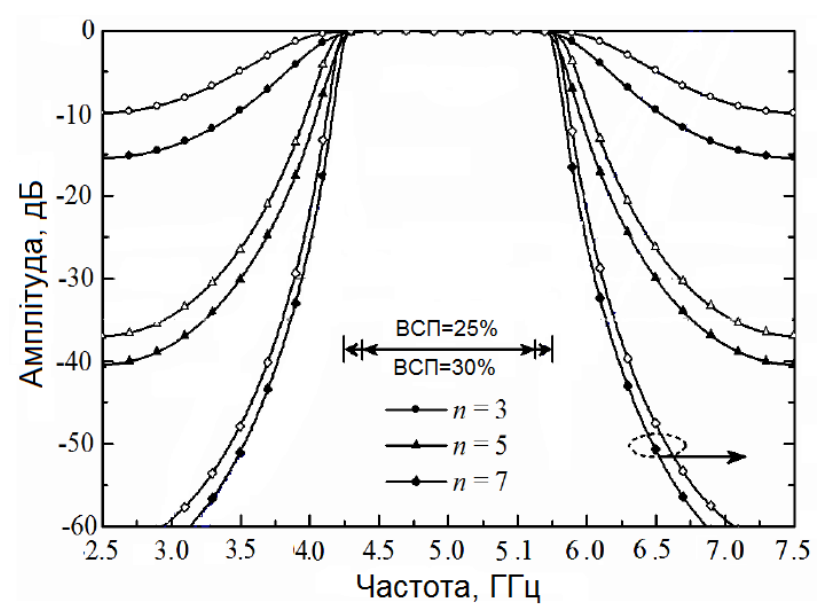

Рис. 2

Таким чином, необхідно обрати найменше n, якщо необхідно суворе дотримання потрібної частотної вибірності у діапазоні частот 4-6 ГГц.

Список літературних джерел

1. Piltyay S., Bulashenko A., Kushnir H., Bulashenko O. (2020) Information resources economy in satellite systems based on new microwave polarizers with tunable posts, Path of Science, Vol. 6, No 11, pp. 5001-5010. http://doi.org/10.22178/pos.55-1.

2. Bulashenko A.V., Piltyay S.I., Kushnir H.S., Bulashenko O.V. (2020) Compact waveguide polarizer with three antiphase posts, Visnyk of Vinnytsia Polytechnical Institute, Vol. 5, pp. 97-104. (in Ukrainian). http://doi.org/10.31649/1997-9266-2020-152-5-97-104.

3. Bulashenko A.V. (2020) Evaluation of D2D Communications in 5G networks, Visnyk NTUU KPI Seriia - Radiotekhnika, Radioaparatobuduvannia, Vol. 81, pp. 21-29. (in Ukrainian). http://doi.org/10.20535/RADAP.2020.81.21-29.

4. Bulashenko A.V. (2021) Combined criterion for the choice of routing based on D2D technology, Radio Electronics, Computer Science, Control, vol. 1, pp. 7-13, April 2021 (in Ukrainian). http://doi.org/10.15588/16073274-2021-1-1.

5. Piltyay S. I., Bulashenko A.V., Demchenko I. V. (2020) Waveguide iris polarizers for Ku-band satellite antenna feeds, Journal of Nano- and Electronic Physics, Vol. 12, No. 5, pp. 05024-1-05024-5, October 2020. http://doi.org/10.21272/jnep.12(5).05024.

6. Piltyay S.I., Bulashenko A.V., Kalinichenko Ye.I., Bulashenko O.V. (2020) High performance waveguide polarizer for satellite information systems, Visnyk Cherkaskogo derzhavnogo tehnologichnogo universitetu, Vol. 4, pp. 14-26. (in Russian). DOI: 10.24025/2306-4412.4.2020.217129.

7. Piltyay S.I., Bulashenko A.V. and Demchenko I. V. (2020) Compact polarizers for satellite information systems, Proceedings of IEEE 
International Conference on Problems of Infocommunications. Science and Technology, Kharkiv, Ukraine, pp. 350-355.

8 Piltyay S.I., Sushko O.Yu., Bulashenko A.V. and Demchenko I. V. (2020) Compact Ku-band iris polarizers for satellite telecommunication systems. Telecommunications and Radio Engineering, Vol 79, No19, pp. 1673-1690. http://doi.org/10.1615/TelecomRadEng.v79.i19.10.

9. Bulashenko A.V., Piltyay S.I., Demchenko I.V. (2020) Analytical technique for iris polarizers development, IEEE International Conference on Problems of Infocommunications. Science and Technology, Kharkiv, Ukraine, pp. 464-469.

10. Piltyay S.I., Bulashenko A.V., Demchenko I.V. (2020) Analytical synthesis of waveguide iris polarizers. Telecommunications and Radio Engineering, Vol. 79, No 18, pp. 1579-1597. http://doi.org/10.1615/TelecomRadEng.v79.i18.10.

11. Bulashenko A.V., Piltyay S.I., Kalinichenko Y.I., Bulashenko O.V. (2020) Tunable square waveguide polarizer with irises and posts. Technical Engineering, Vol. 86, No. 2, pp. 108-116. (in Ukrainian). http://doi.org/10.26642/ten-2020-2(86)-108-116.

12. Piltyay S., Bulashenko A., Kushnir H. and Bulashenko O. (2020) New tunable iris-post square waveguide polarizers for satellite information systems. Proceedings of IEEE 2nd International Conference on Advanced Trends in Information Theory, Kyiv, Ukraine, pp. 342-348. DOI: http://doi.org/10.1109/ATIT50783.2020.9349357.

13. Bulashenko A., Piltyay S., Kalinichenko Ye., Bulashenko O. (2020) Mathematical modeling of iris-post sections for waveguide filters, phase shifters and polarizers, IEEE 2nd International Conference on Advanced Trends in Information Theory, pp. 330-336, Kyiv, Ukraine. http://doi.org/10.1109/ATIT50783.2020.9349321.

14. Bulashenko A.V., Piltyay S.I., Demchenko I.V. (2020) Wave matrix technique for waveguide iris polarizers simulation. Theory, Journal of Nano- and Electronic Physics, Vol. 12, No. 6, pp. 06026-1-06026-5. http://doi.org/10.21272/jnep.12(6).06026.

15. Bulashenko A.V., Piltyay S.I. (2020) Equivalent microwave circuit technique for waveguide iris polarizers development, Visnyk NTUU KPI Seriia - Radiotekhnika, Radioaparatobuduvannia, Vol. 83, pp. 17-28 (2020). http://doi.org/10.20535/RADAP.2020.83.17-28.

16. Bulashenko A.V., Piltyay S.I., Demchenko I.V. (2020) Optimization of a polarizer based on a square waveguide with irises. Science-Based Technologies, Vol. 47, No 3, pp. 287-297. (in Ukrainian). http://doi.org/10.18372/2310-5461.47.14878. 